\title{
Post-Evaluation System of Cold Central-Plant Recycling Technology for Old Asphalt Pavement
}

\author{
Hongjun Jing ${ }^{1,2 *}$, Lichen Song ${ }^{1,2}$, Yue Cong ${ }^{1,2}, \mathrm{Xu} \mathrm{Zhu}^{3}$, Zhuangzhuang Xin ${ }^{4}$ and Baoyu Jing ${ }^{5}$ \\ ${ }^{I}$ College of Architectural and Civil Engineering, Xi'an University of Science and Technology, Xi'an City, Shaanxi Province, 710054, \\ China \\ ${ }^{2}$ Road Engineering Research Center of Xi'an University of Science and Technology, Xi'an City, Shaanxi Province, 710054, China \\ ${ }^{3}$ Ankang City Traffic Construction Quality Supervision Station of Shaanxi Province, Ankang 725000, China \\ ${ }^{4}$ Xianyang Highway Administration Bureau of Shaanxi Province, Xianyang City, Shaanxi Province, 712000, China \\ ${ }^{5}$ University of Illinois at Urbana-Champaign, Urbana, IL 61801, United States
}

Received 19 June 2019; Accepted 1 August 2019

\begin{abstract}
Cold central-plant recycling (CCPR) is a technical method for the repair and maintenance of old asphalt pavement. However, this method lacks a complete evaluation system. In this study, various influencing factors were investigated and analyzed to establish a comprehensive and systematic evaluation system for CCPR pavement. A full-life staged evaluation system for CCPR pavement was established from perspectives of old pavement investigation and design, construction technology, management, and pavement performance and benefits. This evaluation system covered 5 level- 1 indexes, 19 level-2 indexes, and 30 level-3 indexes, which were introduced in the present study. Weights of different indexes were determined by combining various evaluation methods, such as improved analytic hierarchy process and fuzzy comprehensive evaluation, and mutual influences of indexes. The CCPR pavement was evaluated based on the G316 repair and maintenance projects in Hanzhong of Shaanxi Province of China in 2017. Results demonstrate that the performance and benefits of CCPR pavement have the highest weight. Three level-1 indexes, namely, old pavement investigation and design, construction technology, and pavement performance, are evaluated to be good, while benefits and management are excellent. The overall evaluation score is 84.8 , and the overall grade is good. The evaluation results conform to practical engineering situations. The proposed evaluation system can provide references to evaluate CCPR pavement.
\end{abstract}

Keywords: Pavement engineering, Cold central-plant recycling, Full-life analysis, Post-evaluation system, Improved AHP, Fuzzy comprehensive evaluation

\section{Introduction}

Highway engineering has achieved considerable developments with large-scale highway constructions in China. The total mileage of highway maintenance and old pavement failure increases yearly. Due to low technological level and poor quality control in early highway construction, increased traffic volume, and serious overspeed and overload phenomena, asphalt pavements constructed in the early period have been damaged, as manifested by ruts, cracks, and loose structures. Some pavements even have lost usability of highways [1-3]. Many mileages of pavements are currently facing repair or reconstruction. Therefore, strengthening old asphalt pavement recycling and constructing sustainable pavements are of considerable importance.

Cold central-plant recycling (CCPR) mills the entire old pavement through a milling machine and then recycles asphalt pavement materials in a mixing plant to facilitate their combination with a proportion of new aggregates and active fillers under room temperature after crushing and screening. The new mixture is then paved into the structural layer of pavements. Compared with new traditional

*E-mail address: inghongjun@xust.edu.cn

ISSN: 1791-2377@ 2019 School of Science, IHU. All rights reserved.

doi:10.25103/iestr.124.10 pavement, CCPR can recycle and use the waste pavement mixture to the maximum extent. This technology increases resource utilization level of waste materials and maintains good pavement performance [4]. Mixture milling requires no heating, which can effectively reduce greenhouse gas emission and decrease environmental pollution. Owing to short construction periods, cold recycling technology can effectively reduce and increase engineering cost and benefits, respectively. Thus, this technology shows good social benefits.

Considering structural performance and sustainability of pavement, cold recycling technology mills the original pavement and then recycles the old asphalt materials for pavement base and subbase layers. Characteristics of the mixture are conducive to the reduction of bottom-up reflection cracks caused by cracking of base and subbase layers. According to relevant studies, the cold recycling mixing base has longer fatigue life, smaller fatigue injury, and stronger resistance to fatigue failure compared with those of traditional semi-rigid base materials. The mixture of milling materials and additives shows strong resistance to thermal and dry shrinkage [5-6]. The cold recycling mixture that uses cement as additives has relatively low rigidity modulus and resistance to repeated loads but has strong resistance to permanent deformation. The thermal sensitivity and viscous response of the recycling mixture are lowered 
due to the existence of cement bond [7]. Based on the aforementioned characteristics, the cold recycling mixture presents good structural and mechanical properties as the pavement base. Moreover, the net present value of cold recycling pavement is smaller than that of traditionally new pavement, showing some economic advantages. Repair and maintenance of old asphalt pavement based on cold recycling technology can protect the environment, save costs, and prolong the service life of old pavements.

Given that highway engineering is influenced by many factors (e.g., design, construction technology, and environment), some recycling highway projects fail to reach the expected effect. Post-evaluation of highway projects is not only beneficial for the summary of experiences and proposed suggestions but also improves effects, benefits, and influences of projects. On this basis, a comprehensive and systematic post-evaluation system was established. Combined with comprehensive evaluation methods, a systematic objective evaluation analysis of CCPR projects was conducted. This study aims to summarize the advantages and disadvantages in the construction of CCPR highway projects to promote the development of recycling technology.

\section{State of the art}

As a repair and maintenance technological mean, CCPR is characteristic of short construction period, high utilization of old mixing materials, and good environmental and economic effects. Nevertheless, the evaluation system of CCPR has only started. Many scholars have studied relevant indexes and evaluation methods of recycling technology. Based on analyses of lifecycle and lifecycle cost, Li et al. [8] found that most recycled solid wastes performed well in highway pavements from the perspective of economic and environmental effects. The use of recycled solid wastes decreased energy consumption and lowered greenhouse gas emission and cost. Luo et al. [9] analyzed and quantized the long-term field aging of recycled asphalt pavement (RAP) coverage layer based on falling weight deflectometer and climatic data. They found that RAP mixture has the highest aging activation energy and the lowest aging rate. They also concluded that thick mixture ages more slowly than thin mixture, while mixture on the rolling pavement ages more slowly than non-rolled mixture. Sultan et al. [10] evaluated mechanical and structural characteristics of recycled asphalt mixture through a lifecycle cost analysis and found that low cement percentage could improve structural characteristics of recycled asphalt materials. The use of recycled asphalt materials in pavement base not only provides substantial contributions to environmental and natural resource protection but also save considerable construction cost. $\mathrm{Wu}$ et al. [11] observed microstructures of recycled pavement materials and suggested using the California bearing ratio and crushing value to evaluate material performances of cement-stabilized recycled pavement. Their results demonstrated that the performance of recycling mixture can meet requirements of asphalt pavement base and subbase layers. Yu et al. [12] analyzed weights of evaluation indexes of hot central-plant recycling based on the analytic hierarchy process (AHP) and concluded that pavement performance is the primary influencing factor of the technology. Evaluation indexes of highway technology and their weights were determined according to relevant codes [13]. Six evaluation indexes, including pavement quality index, pavement condition index, riding quality index, rutting depth index, skidding resistance index, and pavement structural strength index, were proposed. However, CCPR mixtures are mainly applied to base and subbase layers. The proposed evaluation indexes have poor target performance.

Tabakovic et al. [14] evaluated a series of recycling programs. They found that the combination of cold recycling technology and additives can prolong service life, increase economic benefit, and reduce energy consumption. The importance of preliminary investigation was also introduced. Kim et al. [15] tested dynamic modulus and repeated loads of cold recycling mixture and found that performance characteristics of recycling mixture were influenced by its asphalt content, temperature, and loads. Xiao et al. [16] discussed high- and low-temperature performance grades, energy consumption, and greenhouse gas emission of recycled asphalt mixture. They indicated that the content of aging binder in recycling asphalt mixture could affect energy consumption, greenhouse gas emission, and cost reduction.

Most of these studies apply pavement performance and environmental and economic effects as evaluation indexes, but none of these studies considered influences of factors during highway construction on pavement functions. Currently, studies on evaluation systems of recycling pavement are few, and the evaluation index system lacks complete processes and global characteristics [17-18]. Owing to the characteristics of long duration and multiple influencing factors of highway construction, different factors affect each other, and distinguishing primary from secondary factors is difficult. Previous work may considerably influence future work. On this basis, a full-process comprehensive evaluation system from the beginning of construction to the late operation was constructed in this study. This evaluation system covers factors concerning implementation, benefits, effects, and influences of projects. Based on the evaluation index system, the cold recycling technology, which is influenced by multiple factors, is comprehensively evaluated by combining the improved AHP and fuzzy comprehensive evaluation [19-20]. This method is conducted to analyze the causes of failure, summarize experiences, and provide references for the evaluation of similar engineering construction in the future.

The remainder of this study is organized as follows. Section 3 introduces the principle to establish evaluation indexes and relevant evaluation methods. Section 4 proposes the evaluation system of CCPR technology for old asphalt pavement and analyzes results. Conclusions are summarized in section 5 .

\section{Methodology}

\subsection{Principle of establishing evaluation indexes}

Combining with characteristics of CCPR, the principles used to establish the index system and hierarchical model are introduced as follows.

(1) Principle of practicality: the selected evaluation index shall be able to reflect construction quality and benefits of CCPR practically.

(2) Hierarchy: indexes in the same hierarchy are compared, and the low-level indexes serve for the superior indexes.

(3) Comprehensiveness and systematicness: indexes shall comprehensively reflect the characteristics and influences of the CCPR technology and provide references to the extensive evaluation. 
(4) Operation and feedback principle: all selected indexes shall be able to make effective measurement or statistics. They shall feedback problems in project production.

\subsection{Evaluation method}

Given that indexes in the evaluation system have mutual influence, the weights of different indexes were calculated by combining the improved AHP. Membership of evaluation factors was determined by fuzzy evaluation theory. Moreover, a judgment matrix was constructed and fuzzy operation was implemented to obtain the fuzzy comprehensive evaluation results.

\subsubsection{Evaluation factor set}

$U=\left\{u_{1}, u_{2}, \cdots, u_{n}\right\}$ reflects $n$ indexes in the evaluation system of the CCPR technology, where the value of $n$ is determined by a specific system and is the number of evaluation indexes. Each level of indexes is determined by $m$ secondary indexes, that is, $u_{i}=\left\{u_{i 1}, u_{i 2}, \cdots, u_{i m}\right\}$.

\subsubsection{Establishment of alternative set}

The alternative set is $V=\left\{v_{1}, v_{2}, \cdots, v_{k}\right\}$. The pavement evaluation grades in the CCPR include excellent, good, moderate, relatively poor, and poor. The corresponding alternative set is $V=\{100,80,60,40,20\}$.

\subsubsection{Scoring of evaluation factors}

Indexes in the evaluation system can be divided into qualitative discrete indexes and quantitative continuous indexes [21]. Qualitative discrete indexes are scored by experts, while quantitative continuous indexes are scored according to qualification rate of the test (or calculated) indexes and completion degree of goal. Scores of quantitative continuous indexes might be proportional or negatively proportional to test values (or calculated values) (Fig. 1).

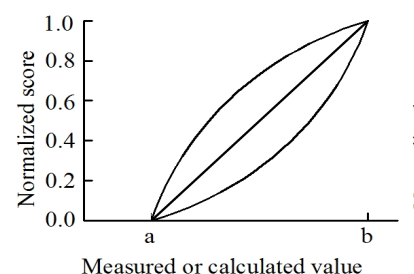

Measured or calculated value

Type 1: Proportional relationship

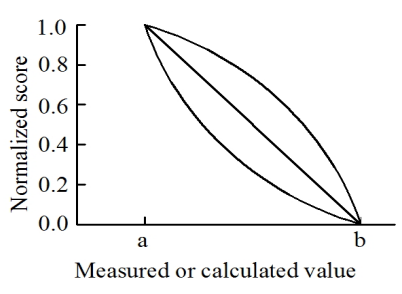

Type 2: Inverse relationship
Fig. 1. Quantitative continuous indexes

\subsubsection{Membership function of indexes}

Membership function of the evaluation indexes can be constructed based on the lifting half trapezoid method.

The membership function of evaluation index score $(x)$ to $v_{k+1}$ in the alternative set is:

$$
r(x)=\left\{\begin{array}{lr}
\frac{x-v_{k}}{v_{k+1}-v_{k}} & \left(v_{k} \leq x \leq v_{k+1}\right) \\
0 & \left(x<v_{k} \text { or } x>v_{k+1}\right)
\end{array}\right.
$$

The membership function of evaluation index score $(x)$ to $v_{k}$ in the alternative set is:

$$
r(x)=\left\{\begin{array}{lr}
\frac{v_{k+1}-x}{v_{k+1}-v_{k}} & \quad\left(v_{k} \leq x \leq v_{k+1}\right) \\
0 & \left(x<v_{k} \text { or } x>v_{k+1}\right)
\end{array}\right.
$$

\subsubsection{Weight analysis of evaluation indexes}

Qualitative and quantitative analyses can be effectively combined by the improved AHP [22-23], which assures systematicness, reasonability, and reliability of the model. Such a combination decreases the disadvantages of traditional AHP, such as complicated calculations.

(1) Construction of a judgment matrix

$k_{i j}=\left\{\begin{array}{cc}0 & i \text { has less influence than } j \\ 1 & i \text { and } j \text { have the same degree of influence } \\ 2 & i \text { has greater influence than } j\end{array}\right.$

where $i, j$ are influencing factors.

The judgment matrix formula is:

$$
\begin{aligned}
& a_{i j}= \begin{cases}r_{i}-r_{j} & \left(r_{i}>r_{j}\right) \\
1 & \left(r_{i}=r_{j}\right) \\
1 /\left(r_{i}-r_{j}\right) & \left(r_{i}<r_{j}\right)\end{cases} \\
& r_{i}=\sum_{h=1}^{n} k_{i h} ; r_{j}=\sum_{h=1}^{n} k_{j h}
\end{aligned}
$$

where $a_{i j}$ is the element of the judgment matrix, $r_{i}, r_{j}$ are indexes of importance indexes, and $n$ is the number of orders in a matrix.

(2) Optimization of judgment matrix

The original matrix is optimized, and a new matrix can be obtained as follows: $B=\left(b_{i j}\right)_{n \times n}$.

$$
b_{i j}=\sqrt[n]{\prod_{i=1}^{n} a_{i j}} / \sqrt[n]{\prod_{j=1}^{n} a_{i j}}
$$

(3) Weights of evaluation indexes

Weights of evaluation indexes can be calculated according to the following equation:

$$
\overline{w_{i}}=\sqrt[n]{\prod_{j=1}^{n} b_{i j}}
$$

which is normalized as:

$w_{i}=\frac{\overline{w_{i}}}{\sum_{i=1}^{n} \bar{w}_{i}},(i=1,2, \cdots, n)$

where $w_{i}$ is the normalized weight of element $i$, and $n$ is the number of indexes.

\subsection{Fuzzy comprehensive evaluation model}

The relation matrix $(p)$ between evaluation indexes and the alternative set is: 


$$
P=\left(\begin{array}{cccc} 
& v_{1} & \cdots & v_{j} \\
u_{1} & p_{11} & \cdots & p_{1 j} \\
\vdots & \vdots & \vdots & \vdots \\
u_{j} & p_{j 1} & \cdots & p_{j j}
\end{array}\right)
$$

where $p_{i j}$ is the membership of $u_{i}$ to $v_{j}$.

The comprehensive evaluation result is:

$$
Y=\bigoplus_{i=1}^{n} w_{i} \otimes p_{i j}
$$

The evaluation grade generally applies the maximum membership degree. However, this method cannot consider all membership information. Thus, evaluation results can be further verified by the asymmetric closeness method [24]:

$$
\left\{\begin{array}{c}
N\left(P, D_{j}\right)=\max _{j \in J_{m}}\left\{N\left(P, D_{j}\right)\right\} \\
N\left(P, D_{j}\right)=1-\frac{1}{m} \sum_{K=1}^{m}\left|\mu_{c}\left(v_{k}\right)-\mu_{D_{J}}\left(v_{k}\right)\right|^{1 / k} \text { or } \\
N\left(P, D_{j}\right)=1-\frac{2}{m(m+1)} \sum_{K=1}^{m}\left|\mu_{c}^{p}\left(v_{k}\right)-\mu_{D_{J}}^{p}\left(v_{k}\right)\right| \cdot k
\end{array}\right.
$$

On this basis, the final evaluation results are obtained.

\subsubsection{Level-3 evaluation indexes}

Level-3 indexes $p_{i j}$ and $w_{i j}$ can be calculated as follows:

$$
\left\{\begin{array}{l}
w_{i j}=\left(w_{i j 1}, w_{i j 2}, \cdots, w_{i j k}\right) \\
p_{i j}=\left[\begin{array}{ccc}
p_{i j 11} & \cdots & p_{i j 15} \\
\vdots & \ddots & \vdots \\
p_{i j k 1} & \cdots & p_{i j k 1}
\end{array}\right] \\
\overline{p_{i j}}=w_{i j} p_{i j}
\end{array}\right.
$$

where $\overline{p_{i j}}$ is evaluation results of level-3 indexes.

\subsubsection{Level-2 evaluation indexes}

Based on $\overline{p_{i j}}$, weight vector $\left(w_{i}\right)$ and relation matrix $\left(p_{i}\right)$ of level-2 evaluation indexes can be calculated as follows:

$\left\{\begin{array}{l}w_{i}=\left(w_{i 1}, w_{i 2}, \cdots, w_{i j}\right) \\ p_{i}=\left(\overline{p_{i 1}}, \overline{p_{i 2}}, \cdots, \overline{p_{i j}}\right)^{T} \\ \overline{p_{i}}=w_{i} p_{i}\end{array}\right.$

where $\overline{p_{i}}$ is the evaluation results of level-2 indexes.

\subsubsection{Level-1 evaluation indexes}

Similarly, the weight $(w)$ and relation matrix $(p)$ of level-1 evaluation indexes can be obtained as follows:

$$
\left\{\begin{array}{l}
w=\left(w_{1}, w_{2}, \cdots, w_{i}\right) \\
p=\left(\overline{p_{1}}, \overline{p_{2}}, \cdots, \overline{p_{i}}\right)^{T} \\
Y=w p
\end{array}\right.
$$

\subsubsection{Comprehensive scores}

The calculation formula of comprehensive score is:

$$
Z=Y V^{T}=\left(y_{1}, y_{2}, y_{3}, y_{4}, y_{5}\right)\left(v_{1}, v_{2}, v_{3}, v_{4}, v_{5}\right)^{T}
$$

\section{Result Analysis and Discussion}

In this study, a case study of maintenance and repair of G316 in Hanzhong, Shaanxi Province of China, in 2017 was conducted. According to the project design, CCPR was applied to base construction in the K2073 + 000-K2079 + 810 and $\mathrm{K} 2080+240-\mathrm{K} 2084+386$ sections. A comprehensive post-evaluation of the project was performed based on the constructed evaluation system by combining the weight vector determination method and fuzzy comprehensive judgment matrix.

\subsection{Analysis of evaluation indexes}

Quality and benefits of highway projects are formed in all stages throughout the service life. The final project quality is not only formed in one stage but is determined by the entire production process. A comprehensive evaluation requires not only post-evaluations of constructed pavement quality and benefits but also assessments of all stages in the entire construction process. The comprehensive evaluation process refers to the evaluation from design and construction to formation, implementation, and service of the entire project. In this study, an evaluation system from the beginning of construction to late management was proposed for full-life comprehensive evaluation, with extensive considerations to all production stages of the project. Based on summary analysis and consultation of experts, the post-evaluation content was divided into five types of indexes: old pavement investigation and pavement design (hereinafter referred as investigation \& design), construction technology, pavement performance, management, and benefits. The evaluation process is shown in Fig. 2.

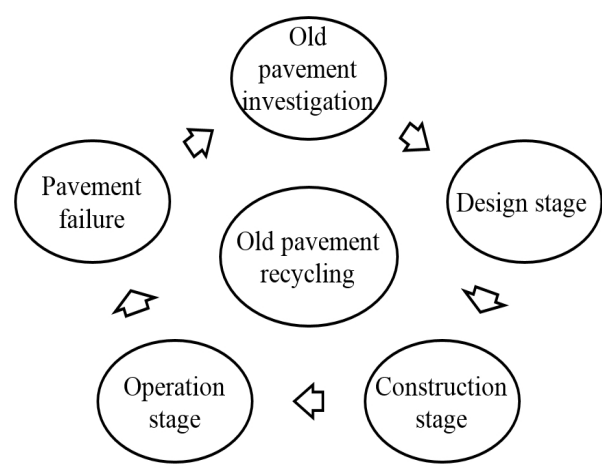

Fig. 2. Full-life evaluation process of old pavement recycling

\subsubsection{Investigation \& design}

CCPR is an asphalt pavement recycling technology that constructs the structural layer of pavement under room temperature. In constructing recycled asphalt pavement, the construction shall be designed according to historical information of highway grade, traffic volume, and the original pavement. The post-evaluation indexes of investigation $\&$ design were divided into four parts.

(1) The main evaluation reference of existing pavement investigation is whether comprehensiveness of the original pavement investigation and investigation items are targeted at design demands and complete degree of disease processing. 
(2) Project design indicates whether the recycling project meets the type of original pavement disease. Late observation is used to determine whether the original program satisfies technological and economic requirements.

(3) Thickness design. Given that thickness of the base is the main influencing factor of pavement structures, pavement thickness can simultaneously reflect deflection value of pavement design and bottom layer tensile stress. Moreover, thick layers can protect bases from damages and reduce reflection cracks. However, excessively thick pavement cannot meet economic effects. Hence, reasonability of design thickness shall be evaluated by the late pavement performance. The design and evaluation of thickness require a comprehensive consideration to requirements on advanced technologies, safety and reliability, applicability and duration, reasonability, and economic efficiency. Thickness design is a qualitative index.

(4) Material design. This index is evaluated by type and gradation of additives. Pavement material is the main influencing factor of pavement performance, while pavement performance and service life are influenced by pavement materials. Hence, reasonability of material design shall be evaluated by late pavement performance.

\subsubsection{Construction technology}

Construction technology influences the engineering quality and project schedule. A good construction technology can increase pavement performance and benefits of highways. In this study, influencing factors were divided into four classes, including milling material quality, aggregate mixing, transportation, and paving and rolling.

(1) Milling material quality is sensitive to many factors. Milling speed, grain size, and temperature were chosen in the present study. The three indexes have a mutual influence. Milling speed and temperature determine the grain size of old asphalt mixture. Hence, milling technology and material quality shall be comprehensively evaluated.

(2) Aggregate mixing level determines the quality of mixing materials. This mixing level is determined by three evaluation factors, including control level of mixing station, aggregate output, and mixing ratio.

(3) Transport of mixing material is related to the efficiency of construction procedure and evaluated by transport time. If the waiting time is extremely long, then the quality of mixing materials will deteriorate. Slow transport may delay the construction schedule, and reasonable arrangement of transport schedule is necessary.

(4) Paving and rolling are evaluated according to paving speed and compaction degree (thickness).

\subsubsection{Pavement performance}

In the CCPR technology, the old pavement is milled as pavement base or subbase. Structural and mechanical properties of pavement are different from those of traditional semi-rigid base due to the existence of old asphalt mixing materials. After some years of service, structural and mechanical properties of pavement decline due to changing environments, such as freezing-thawing cycle and rainfall infiltration. Performance indexes of pavement base directly influence the overall use of pavement. For example, reflection cracks are easily produced in the pavement, and the service life of pavements is shortened due to the presence of low bottom layer tensile stress. Post-evaluation of pavement must consider deflection value, strength, and deformation under influences of multiple conditions.
(1) Deflection index. Deflection value represents the vertical displacement of pavement structure under loads and reflects the overall rigidity of pavement structure, that is, rigidity of the surface and base layers.

(2) Strength performance. Old milling materials are used as the pavement base, and strength changes in the pavement base after a certain period are observed. Based on measurements, compressive and splitting strengths of materials conform to the required proportion in the code. Both were used to evaluate the strength performance of old asphalt mixing materials as pavement base.

(3) Deformation performance. Pavement deformation directly influences driving comfort and safety. This factor cannot be neglected in the post-evaluation of recycled pavement. Pavement deformation is mainly manifested by ruts and cracks. Fewer ruts and cracks result in improved pavement deformation.

\subsubsection{Management level}

Construction management is an overall project. Management level or quality often influences the entire engineering field. Management might be explicit or fuzzy and inexplicit. In this study, construction management was divided into five influencing factors, namely, material, personnel, machine, safety, and traffic.

(1) Material management. This factor is evaluated by storage site and conditions of milling materials and new aggregates from old asphalt pavement. The storage site can influence the transport distance and time of materials. Storage conditions can also affect changes in material properties. Rainfall can increase moisture content in materials without coverage.

(2) Personnel management. This factor is divided into technological level and quality of construction workers. Although personnel management is ambiguous, it can directly influence management and project qualities.

(3) Machine management. Conditions, models, and cooperation of machines determine the final construction quality.

(4) Safety management. Life and property safety of humans is the most important among project priorities. Safety management of the project cannot be neglected.

(5) Traffic management. Traffic jam during repair and maintenance due to old pavements is inevitable. Effective traffic management is beneficial to relieve traffic jam and accidents. Evaluation of traffic management is mainly based on traffic jam duration.

\subsubsection{Benefits}

As a repair and maintenance mean of highway projects, cold recycling technology can effectively protect the environment and save resources. This technology is conducive to saving engineering construction costs. Benefits of CCPR pavement were analyzed from social, economic, and environmental aspects.

(1) Social benefits. The cold recycling technology can effectively shorten construction schedule and closing hours and create new employment posts.

(2) Economic benefits. The cold recycling base saves consumption of new aggregate and cost for materials due to the large-scale use of recycled asphalt pavement materials. Thus, outstanding economic benefits are obtained.

(3) Environmental benefits. Recycled use of asphalt pavement wastes in cold recycling technology relieves environmental pollution and decreases the exploitation of new aggregates. Thus, good environmental benefits are 
attained.

Table 1. Evaluation system

\begin{tabular}{|c|c|c|c|}
\hline Level-1 indexes & Level-2 indexes & Level-3 indexes & \\
\hline \multirow[t]{3}{*}{ Investigation $\&$ design $u_{1}$} & $\begin{array}{l}\text { Old pavement investigation } u_{11} \\
\text { Program selection } u_{12}\end{array}$ & $\begin{array}{l}- \\
-\end{array}$ & $\begin{array}{l}\text { Qualitative } \\
\text { Qualitative }\end{array}$ \\
\hline & Thickness design $u_{13}$ & $\begin{array}{l}\text { Base thickness } u_{131} \\
\text { Surface thickness } u_{132}\end{array}$ & $\begin{array}{l}\text { Qualitative } \\
\text { Qualitative }\end{array}$ \\
\hline & Material design $u_{14}$ & $\begin{array}{l}\text { Type of additives } u_{141} \\
\text { Gradation of materials } u_{142}\end{array}$ & $\begin{array}{l}\text { Qualitative } \\
\text { Qualitative }\end{array}$ \\
\hline \multirow[t]{4}{*}{ Construction technology $u_{2}$} & Milling $u_{21}$ & $\begin{array}{l}\text { Depth } u_{211} \\
\text { Grain size } u_{212} \\
\text { Temperature } u_{213}\end{array}$ & $\begin{array}{l}\text { Quantitative } \\
\text { Quantitative } \\
\text { Quantitative }\end{array}$ \\
\hline & Aggregate mixing $u_{22}$ & $\begin{array}{l}\text { Mixing plant control } u_{221} \\
\text { Mixture yield } u_{222} \\
\text { Mixing ratio } u_{223}\end{array}$ & $\begin{array}{l}\text { Qualitative } \\
\text { Quantitative } \\
\text { Quantitative }\end{array}$ \\
\hline & Transportation $u_{23}$ & Transportation time $u_{231}$ & Quantitative \\
\hline & Paving and rolling $u_{24}$ & $\begin{array}{l}\text { Paving speed } u_{241} \\
\text { Compaction degree (thickness) } u_{242}\end{array}$ & $\begin{array}{l}\text { Quantitative } \\
\text { Quantitative }\end{array}$ \\
\hline \multirow[t]{3}{*}{ Pavement performance $u_{3}$} & Deflection $u_{31}$ & - & Quantitative \\
\hline & Strength $u_{32}$ & $\begin{array}{l}\text { Compressive strength } u_{321} \\
\text { Splitting strength } u_{322}\end{array}$ & $\begin{array}{l}\text { Quantitative } \\
\text { Quantitative }\end{array}$ \\
\hline & Deformation $u_{33}$ & $\begin{array}{l}\text { Rut depth } u_{331} \\
\text { Fatigue cracking } u_{332}\end{array}$ & $\begin{array}{l}\text { Quantitative } \\
\text { Quantitative }\end{array}$ \\
\hline \multirow[t]{5}{*}{ Management level $u_{4}$} & Material management $u_{41}$ & $\begin{array}{l}\text { Storage site } u_{411} \\
\text { Storage condition } u_{412}\end{array}$ & $\begin{array}{l}\text { Qualitative } \\
\text { Qualitative }\end{array}$ \\
\hline & Personnel management $u_{42}$ & $\begin{array}{l}\text { Qualification } u_{421} \\
\text { Technological level } u_{422}\end{array}$ & $\begin{array}{l}\text { Quantitative } \\
\text { Quantitative }\end{array}$ \\
\hline & Machine management $u_{43}$ & Model and cooperation $u_{431}$ & Qualitative \\
\hline & Safety management $u_{44}$ & Incidence of traffic accidents $u_{441}$ & Quantitative \\
\hline & Traffic management $u_{45}$ & Traffic jam $u_{451}$ & Quantitative \\
\hline \multirow[t]{3}{*}{ Benefits $u_{5}$} & Social benefits $u_{51}$ & $\begin{array}{l}\text { Create new employment posts } u_{511} \\
\text { Shorten closing hours } u_{512}\end{array}$ & $\begin{array}{l}\text { Quantitative } \\
\text { Quantitative }\end{array}$ \\
\hline & Economic benefits $u_{52}$ & $\begin{array}{l}\text { Save time cost } u_{521} \\
\text { Save construction cost } u_{522}\end{array}$ & $\begin{array}{l}\text { Quantitative } \\
\text { Quantitative }\end{array}$ \\
\hline & Environmental benefits $u_{53}$ & $\begin{array}{l}\text { Energy consumption and greenhouse gas emission } u_{531} \\
\text { Dosage of old asphalt mixture } u_{532}\end{array}$ & $\begin{array}{l}\text { Quantitative } \\
\text { Quantitative }\end{array}$ \\
\hline
\end{tabular}

Given that highway construction is time-consuming, the benefits of highway construction are affected by various factors in early construction. Although recycling technology generally shows good benefits, this technology is still indispensable to post-evaluation. Thus, post-evaluation is conducive to the summary of experiences and increased benefits.

Based on the analysis of the aforementioned indexes, the post-evaluation system of the CCPR technology is shown in Table 1.

In Table 1, level-1 index $u_{i}$ considers all stages from the beginning to the operation of CCPR projects. Level-2 index $u_{i j}$ includes various factors that influence scoring of level-1 indexes. Level-3 indexes are the evaluation factors below level-2 indexes.

\subsection{Weights of indexes}

Based on the aforementioned method, weights of indexes were calculated according to Equations (3-8), and the results are shown in Table 2.

Table 2 shows that weights of design indexes are higher than those of investigation indexes. Weights of aggregate processing and construction are high in construction technology. Weights of level-2 indexes of pavement performance are equal, indicating that pavement strength and deformation can considerably influence pavement 
performance. Management level is mostly influenced by managers. Moreover, safety factors cannot be neglected. Economic and environmental benefits of CCPR technology are slightly higher than social benefits. However, various benefits facilitate each other.

Table 2. Weights of indexes

\begin{tabular}{l|l}
\hline & $w_{13}=(0.373,0.627)$ \\
& $w_{14}=(0.5,0.5)$ \\
& $w_{21}=(0.571,0.286,0.143) \quad w_{22}=(0.142,0.429,0.429) \quad w_{24}=(0.5,0.5)$ \\
& $w_{32}=(0.5,0.5) w_{33}=(0.5,0.5)$ \\
& $w_{41}=(0.5,0.5) w_{42}=(0.5,0.5)$ \\
& $w_{51}=(0.5,0.5) w_{52}=(0.373,0.627) \quad w_{53}=(0.373,0.627)$ \\
\hline \multirow{3}{*}{ Weights of level-2 indexes } & $w_{1}=(0.076,0.308,0.308,0.308)$ \\
& $w_{2}=(0.382,0.238,0.077,0.304)$ \\
& $w_{3}=(0.33,0.33,0.33)$ \\
& $w_{4}=(0.143,0.205,0.170,0.323,0.159)$ \\
\hline Weights of level-1 indexes & $w_{5}=(0.142,0.429,0.429)$ \\
\hline
\end{tabular}

\subsection{Level-3 evaluation results}

Level-3 evaluation results of CCPR technology were obtained (Table 3 ) based on the evaluation system model and Equation (12).

Table 3. Level-3 evaluation results

\begin{tabular}{l|l|l}
\hline Level-1 indexes & Level-2 indexes & Level-3 indexes \\
\hline & Old pavement investigation & $\bar{p}=(0.45,0.55,0,0,0)$ \\
& Program selection & $\bar{p}=(0,1,0,0,0)$ \\
& Thickness design & $\bar{p}=w_{13} p_{13}=(0.625,0.375,0,0,0)$ \\
& Material design & $\bar{p}=w_{14} p_{14}=(0.407,0.593,0,0,0)$ \\
\hline \multirow{3}{*}{ Construction technology } & Milling & $\bar{p}=w_{21} p_{21}=(0.0715,0.857,0.0715,0,0)$ \\
& Aggregate mixing & $\bar{p}=w_{22} p_{22}=(0.543,0.457,0,0,0)$ \\
& Transportation & $\bar{p}=(1,0,0,0,0)$ \\
& Paving and rolling & $\bar{p}=w_{24} p_{24}=(0.375,0.625,0,0,0)$ \\
\hline
\end{tabular}

Note: Only calculations of investigation \& design and construction technology are listed in Table 3 . The calculation process of the remaining indexes is the same.

Table 3 shows that the old pavement is evaluated good by an investigation, and the maximum membership degree is 0.55. Thickness design is evaluated excellent and material design is good. In construction technology, milling and paving and rolling are good. Mixing and transportation are evaluated excellent.

\subsection{Level-2 evaluation results}

Level-2 evaluation results of CCPR technology were obtained (Table 4) based on Equation (13).

Table 4. Level-2 evaluation results

\begin{tabular}{l|l}
\hline Level-1 indexes & Level-2 indexes \\
\hline Investigation \& design & $\bar{p}=w_{1} p_{1}=(0.66,0.34,0,0,0)$ \\
\hline Construction technology & $\bar{p}=w_{2} p_{2}=(0.348,0.626,0.027,0,0)$ \\
\hline Pavement performance & $\bar{p}=w_{3} p_{3}=(0,0.652,0.348,0,0)$ \\
\hline Management level & $\bar{p}=w_{4} p_{4}=(0.505,0.285,0.21,0,0)$ \\
\hline Benefits & $\bar{p}=w_{5} p_{5}=(0.69,0.3,0.01,0,0)$ \\
\hline
\end{tabular}

Table 4 shows that investigation \& design is generally evaluated excellent. Construction technology is good, and its maximum membership degree is 0.626 . The membership degree of construction technology to "moderate" is 0.027 , indicating that some factors must be improved in construction technology. Pavement performance is good, and the maximum membership degree is 0.652 . The membership degree of pavement performance to "moderate" is 0.348 , which is related to the sensitivity of CCPR pavement to natural and traffic load changes in the late stage. Pavement performance deteriorates to some extent with time. The management level is evaluated excellent. However, certain proportions of "good" and "moderate" evaluation results are obtained in management due to fuzziness. This finding indicates some space for the improvement of management level. Benefits are evaluated "excellent" and membership degree is high, indicating that social and economic benefits of the CCPR technology are evident. CCPR technology has considerable advantages in environmental protection and energy-saving.

\subsection{Level-1 evaluation results}

Level-1 evaluation results of CCPR technology were obtained based on Equation (14), and the results are shown in Table 5.

Table 5 shows that the CCPR technology is comprehensively evaluated good, and the membership degree to "excellent" is 0.4 . This result accounts for a large proportion, indicating that the evaluation grade of the project has an upward trend. The overall evaluation is good. 
Table 5. Level-1 evaluation results

\begin{tabular}{l|l}
\hline \multirow{2}{*}{ Comprehensive evaluation } & Level-1 evaluation results \\
\cline { 2 - 2 } & $\bar{p}=w p=(0.4,0.44,0.16,0,0)$ \\
\hline
\end{tabular}

Table 6. Scoring results

\begin{tabular}{l|l|l}
\hline \multicolumn{2}{l|}{ Type of indexes } & Scores \\
\hline & Investigation \& design & 93.2 \\
& Construction technology & 86.5 \\
Level-1 indexes & Pavement performance & 73.04 \\
& Management level & 83.8 \\
& Benefits & 93.6 \\
\hline Comprehensive evaluation & Comprehensive scores & 84.8 \\
\hline
\end{tabular}

\subsection{Comprehensive evaluation}

Evaluation results were analyzed by the asymmetric closeness method based on Equation (11). Information in $p_{i}$ was comprehensively considered. Finally, results are found to be consistent with the fuzzy comprehensive judgment results. The calculated results (maximum) of the asymmetric closeness method are shown as follows:

$$
\begin{aligned}
& N\left(P_{1}, D_{1}\right)=0.815 \\
& N\left(P_{2}, D_{1}\right)=0.748 \\
& N\left(P_{3}, D_{1}\right)=0.741 \\
& N\left(P_{4}, D_{1}\right)=0.682 \\
& N\left(P_{5}, D_{1}\right)=0.785 \\
& N\left(P, D_{1}\right)=0.662
\end{aligned}
$$

Combining with the calculation formula (15), scores and comprehensive scores of level-1 indexes were calculated (Table 6).

According to the calculation results of asymmetric closeness method, evaluation results considering membership degree of different evaluation grades are still consistent with fuzzy comprehensive evaluation results. This finding proves that fuzzy comprehensive evaluation results are extensive. Table 6 shows that scores of construction technology, pavement performance, and management level are relatively low and can be considerably improved. Scores of different indexes can reflect evaluation indexes intuitively.

\subsection{Results analysis}

Evaluation results were analyzed based on construction technology. Construction quality during the construction process was tested according to code requirements. The analysis of evaluation results is shown in Table 7.

Table 7. Analysis of results

\begin{tabular}{l|l|l}
\hline Name of indexes & \multicolumn{1}{|c}{ Analysis and evaluation } & Evaluation grade \\
\hline \multirow{3}{*}{ Milling } & $\begin{array}{l}\text { Milling temperature }<40{ }^{\circ} \mathrm{C} . \\
\text { Speed is controlled at } 5-5.5 \mathrm{~m} / \mathrm{min} . \\
\text { proportion of ultra-large grain size }(>31.5 \mathrm{~mm}) \text { is }<7 \% . \\
\text { Mixing plant control: ultra-large grains are crushed. } \\
\text { The mixing equipment is adjusted to determine proportion of supply in warehouse. } \\
\text { The mixing ratio is good. RAP:gravel:debris }=55: 30: 15 . \text { Yield is supplied in time. } \\
\text { Transportation time }<1.5 \mathrm{~h} .\end{array}$ \\
Transportation & $\begin{array}{l}\text { Paving speed: } 1.5-2 \mathrm{~m} / \mathrm{min} . \\
\text { Local separation is observed, and the overall performance is good. } \\
\text { Pass rates of flatness and cross slope are } 97.5 \% \text { and } 92 \%, \text { respectively. } \\
\text { Compaction test has } 225 \text { points with a pass rate of } 100 \% .\end{array}$ & Excellent \\
\hline
\end{tabular}

Based on the evaluation system and method, this index score is $Z_{2}=86.5$, and the maximum membership degree is 0.626. Construction technology is also good. According to the process control of construction technology and test results of compactness, thickness, and flatness of pavement base, construction technology can generally satisfy code and design requirements and conform to contrast analysis of evaluation results.

\section{Conclusions}

In this study, various indexes were analyzed and discussed through comprehensive investigation and summary to establish a complete evaluation system of CCPR pavement. The following major conclusions could be drawn:

(1) The evaluation process of CCPR pavement has been determined and interpreted. Five level-1 indexes, which include investigation \& design, construction technology, pavement performance, management, and benefits, have been proposed. The comprehensive evaluation system of CCPR pavement has been established.

(2) Weights of indexes have been calculated by the improved AHP. Results indicate that pavement performance and benefit show the highest weights. Quantitative indexes are scored through test and calculation of pass rate (or completion degree), which decreases subjectivity of scoring. Moreover, membership degrees of different indexes are tested by asymmetric closeness method. With comprehensive consideration to information of $p_{i}$, the final evaluation results conform to the fuzzy comprehensive evaluation results.

(3) Based on a case study, indexes of CCPR pavement have been considered by fuzzy comprehensive evaluation. The evaluation results show that level-1 indexes are good or high, and the final comprehensive score is 84.8. The maximum membership degree is 0.44 , and the evaluation grade is good. Case study results conform well to practical situations. Results demonstrate that the proposed evaluation system is comprehensive and its feedback can provide references for the evaluation of CCPR technology.

Overall, the proposed evaluation system covers the entire process and considers the construction lifecycle and mutual influence of indexes. The evaluation system can provide a systematic analysis on the implementation, benefits, effects, and influences of projects. The proposed evaluation system lays the foundation for the assessment and analysis of CCPR repair and maintenance. However, given that scoring of some indexes is fuzzy and highly sensitive to subjective factors, calculation of these indexes is still challenging. Future studies shall strengthen investigation and analysis of the CCPR technology, provide a perfect scoring method of 
fuzzy indexes to decrease fuzziness, and compile a computer program for the convenience of evaluation.
This is an Open Access article distributed under the terms of the Creative Commons Attribution License

\section{References}

1. Xiao, F. P., Yao, S. L., Wang, J. G., Li, X. H., Amirkhanian, S., “A literature review on cold recycling technology of asphalt pavement". Construction and Building Materials, 180, 2018, pp.579-604.

2. Apeagyei, A. K., Diefenderfer, B. K., "Evaluation of cold in-place and cold central-plant recycling methods using laboratory testing of field-cored specimens". Journal of Materials in Civil Engineering, 25(11), 2013, pp.1712-1720.

3. Wang, T., Xiao, F. P., Zhu, X. Y., Huang, B. S., Wang, J. G., Amirkhanian, S., "Energy consumption and environmental impact of rubberized asphalt pavement". Journal of Cleaner Production, 180, 2018, pp.139-158.

4. Díaz-Sánchez, M. A., Timm, D. H., Diefenderfer, B. K., "Structural coefficients of cold central-plant recycled asphalt mixtures". Journal of Transportation Engineering, Part A: Systems, 143(6), 2017, pp.04017019.

5. Gu, F., Ma, W. Y., West R. C., Taylor, A. J., Zhang, Y. Q., "Structural performance and sustainability assessment of cold central-plant and in-place recycled asphalt pavements: A case study". Journal of Cleaner Production, 208, 2019, pp.1513-1523.

6. Wang, L., "Research on asphalt pavement cold In-place recycling technique using cement as additive". Master thesis of Hebei University of Technology, China, 2013, pp.41-46.

7. Stimilli, A., Ferrotti, G., Graziani, A., Canestrari, F., "Performance evaluation of a cold-recycled mixture containing high percentage of reclaimed asphalt". Road Materials and Pavement Design, 14(s1), 2013, pp.149-161.

8. Li, J., Xiao, F. P., Zhang, L. F., Amirkhanian, S. N., "Life cycle assessment and life cycle cost analysis of recycled solid waste materials in highway pavement: A review". Journal of Cleaner Production, 233, 2019, pp.1182-1206.

9. Luo, X., Gu, F., Zhang, Y. Q., Lytton, R. L., Birgisson, B., "Kineticsbased aging evaluation of in-service recycled asphalt pavement". Journal of Cleaner Production, 200, 2018, pp.934-944.

10. Sultan, S. A., Guo, Z. Y., "Evaluating the performance of sustainable perpetual pavements using recycled asphalt pavement in China". International Journal of Transportation Science and Technology, 5, 2016, pp.200-209.

11. Wu, J. M., Zong, W., "Performance of cement stabilized secondary recycling pavement materials". Journal of Chang'an University (Natural Science Edition), 31(5), 2011, pp.7-11+32.

12. Yu, L., Wu, W. J., Diao, J. D., Bao, L. S., Li, Q. G., "Weighing analysis on assessment indexes of hot-in plant recycling technology for asphalt pavement based on analytic hierarchy procedure" Journal of Shenyang Jianzhu University (Natural Science), 30(5), 2014, pp.842-849.
13. Industry Standards of the People's Republic of China, "Highway performance assessment standards: JTG 5210-2018”. Beijing: Ministry of Transport of the People's Republic of China Press, China, 2018, pp.17-21.

14. Tabaković, A., McNally, C., Fallon, E., "Specification development for cold in-situ recycling of asphalt". Construction and Building Materials, 102, 2016, pp.318-328.

15. Kim, Y., Lee, H. D., Heitzman, M., "Dynamic modulus and repeated load tests of cold in-place recycling mixtures using foamed asphalt". Journal of Materials in Civil Engineering, 21(6), 2009, pp.279-285.

16. Xiao, F. P., Su, N. Y., Yao, S. L., Amirkhanian, S., Wang, J. G., "Performance grades, environmental and economic investigations of reclaimed asphalt pavement materials". Journal of Cleaner Production, 211, 2019, pp.1299-1312.

17. Wu, W. J., "Research on Post-evaluation of Hot In-place Recycling Technology". Master thesis of Shenyang Jianzhu University, China, 2014, pp.13-24.

18. Wu, Z. Y., Wu, H. P., "The construction technology and economic benefits of the cold in-place recycling using cement as additive". Highway Engineering, 36(4), 2011, pp.161-163.

19. Zhang, T., Ma, R. G., "Multi-level fuzzy comprehensive evaluation method of lead performance for high-speed railway". Journal of Traffic and Transportation Engineering, 11(2), 2011, pp.97-101.

20. Gnanavelbabu, A., Arunagiri, P., "Ranking of MUDA using AHP and fuzzy AHP algorithm". Materials Today: Proceedings, 5, 2018, pp.13406-13412.

21. Wang, Y. M., Wang, B. G., "Fuzzy evaluation method of scouring stability on soil subgrade slope". China Journal of Highway and Transport, 18(1), 2005, pp.24-29.

22. Jha, M. K., "Feasibility of computer visualization in high way development: a fuzzy logic-based approach". Computer-Aided Civil and Infrastructure Engineering, 21(2), 2006, pp.136-147.

23. Liu, M. Y., Lin, C., Gao, H. W., "Comprehensive fuzzy assessment on the life-cycle environment impact of bridges". China Civil Engineer Journal, 42(1), 2009, pp.55-59.

24. Lü, Y. Z., "Research on reliability evaluation and remaining service forecast of existing concrete bridge". Doctoral Dissertation of Chang'an University, China, 2006, pp.125-130. 